\title{
Design of Load Frequency Controllers for Interconnected Power Systems with Superconducting Magnetic Energy Storage Units using Bat Algorithm
}

\author{
S. Ramesh kumar ${ }^{1}$, S. Ganapathy ${ }^{2}$ \\ ${ }^{I}$ (Assistant Professor / Dept. of Electrical Engineering, Annamalai University, Tamilnadu, India) \\ ${ }_{2}^{2}$ (Professor / Dept. of Electrical Engineering, Annamalai University, Tamilnadu, India)
}

\begin{abstract}
An optimization algorithm based on the echolocation behavior of bats is proposed for improving the load-frequency control (LFC) of interconnected power systems. A maiden attempt is made to highlight the effectiveness of Bat Algorithm in optimizing the controller parameters in load frequency control. The proposed algorithm is applied to a two area interconnected power system with Superconducting Magnetic Energy Storage (SMES) unit. The Superconducting Magnetic Energy Storage unit improves the transients of frequency and tieline power deviations against small load changes by favorable damping effect. The performance of the Bat algorithm is analyzed and simulation study is presented. The simulation results confirm the effectiveness of the proposed algorithm through fast damping steady state deviations in power and frequency in the presence of step load disturbance.
\end{abstract}

Keywords: Bat algorithm, Interconnected power system, Load Frequency Control, Superconducting Magnetic Energy Storage

\section{INTRODUCTION}

Load frequency control introduces as the most significant term in power system so as to supply reliable electric power with better quality. Modern power systems are interconnected units in which the electrical power is transferred between them. Load Frequency Control plays a vital role in power system because of its duty to maintain frequency and transferred power in their pre-scheduled value, in normal condition and in case of slight deviations of the load. LFC is a control system with three main objectives as mentioned below:

i). Maintaining system frequency in its nominal value.

ii). Maintaining the power transfer between the areas.

iii). Maintaining generation in each unit within an economically suitable value

A lot of studies have been performed about LFC in the past decades [1,2]. Several different control strategies have been applied to achieve better performance of power system. Most of these are based on classical proportional plus integral (PI) techniques due to the simplicity, ease of implementation, robustness and decentralized nature of control strategy. However, even in the case of small load disturbances and with the optimized gains for the PI controller, the frequency oscillations and tie-line power deviations persist for a long duration. In these situations, the governor system may no longer be able to absorb the frequency fluctuations due to its slow response. Thus, to compensate for the sudden load changes, an active power source with fast response such as a Superconducting Magnetic Energy Storage unit is expected to be the most effective counter measure [3].

The Classical optimization approach for controller gains is a trial and error method and extremely time consuming when several parameters have to be optimized simultaneously and provides suboptimal result. In view of aforementioned limitations, a flexible algorithm to obtain optimal gains is very important. Different intelligent controllers have been used in the LFC of isolated as well as interconnected power systems [2]. Bat Algorithm (BA) [4] is relatively new metaheuristic optimization method compared with other biological inspired optimization methods. The Bat Algorithm has been successfully applied to solve tough optimization problems such as continuous mathematical functions [5], industrial problems [6], and management problems [7] and in microelectronic applications [8]. Because of the superiority of Bat Algorithm in optimization, it has been applied to the proposed model.

A design of Bat Algorithm based proportional plus integral controller has been presented in this paper. The proposed controller has been applied to an interconnected two area thermal power system with SMES unit.

II.

POWER SYSTEM MODEL

The power system model under study in this paper consists of two control areas connected by a tie line as shown in the Fig.1. Each of the control area composes of two thermal generating units, one having a reheat turbine and the other without reheat turbine along with SMES unit. 
Fast acting energy storage devices, such as SMES, can effectively damp out power frequency and tieline power oscillations caused by small load disturbances .The SMES unit has a superconducting coil. This coil can be charged from the grid during normal operating conditions. After being charged the coil conducts current, which supports the electromagnetic field. When the load demand increases the energy stored in the coil is released to the grid. As the control mechanism brings the system to its new equilibrium condition the superconducting coil charges to its full value. Similarly during release of loads, the superconducting coil gets charged absorbing the excess energy in the system. The absorbed excess energy is released back after the system returns to its steady state.In LFC operation, the dc voltage Ed across the super-conducting inductor is continuously controlled depending on the sensed area control error (ACE) signal [3]. In this study, inductor voltage deviation of SMES unit of each area is based on ACE of the same area in power system. Moreover, the inductor current deviation is used as a negative feedback signal in the SMES control loop. So, the current variable of SMES unit is intended to be settling to its steady state value.

The transfer function model used for the power system model is shown in Fig.2. SMES unit with suitable control can effectively reduce the frequency and tie-line power oscillations following sudden small load perturbations in power system [3]. This method of improving the load frequency control of power systems has the advantage that it does not require the governor or any other part of the power system to perform any sophisticated control actions.

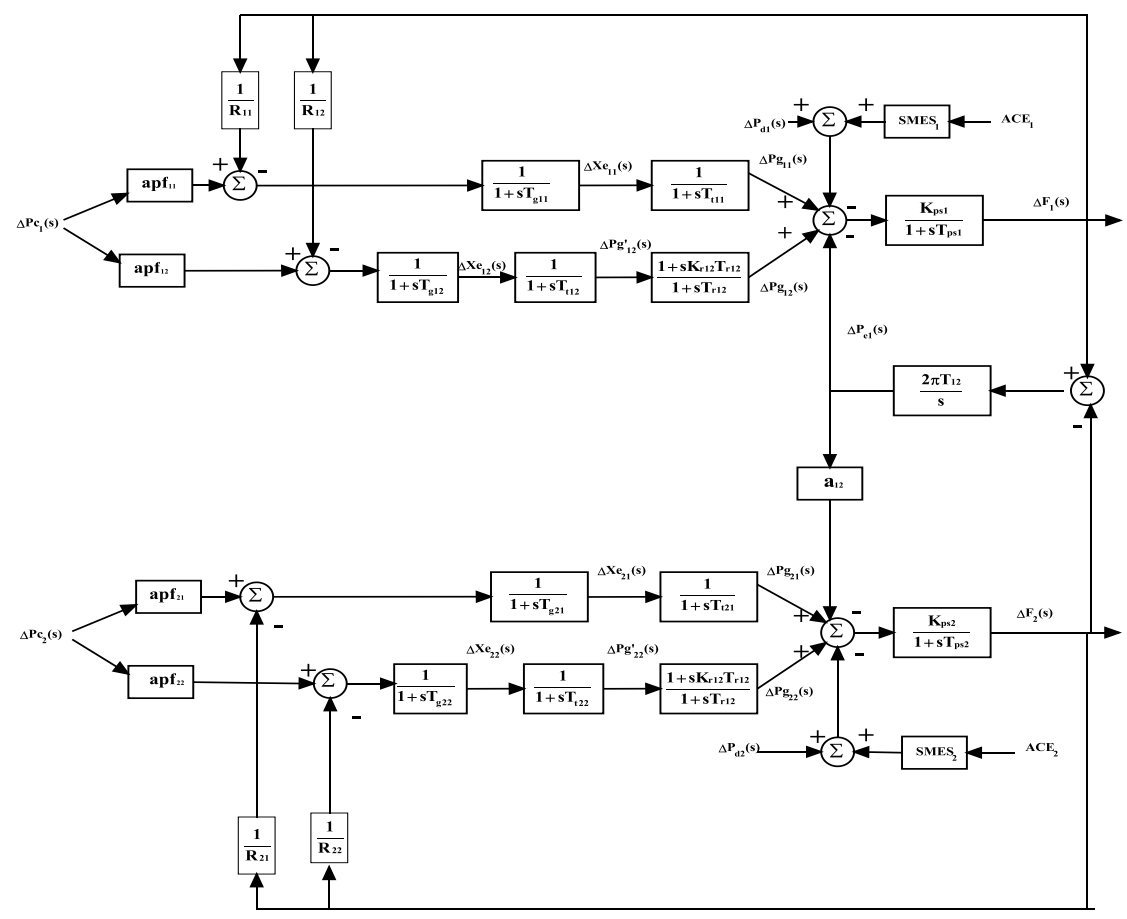

Fig.1. Block diagram of a two - area interconnected thermal power system with SMES units

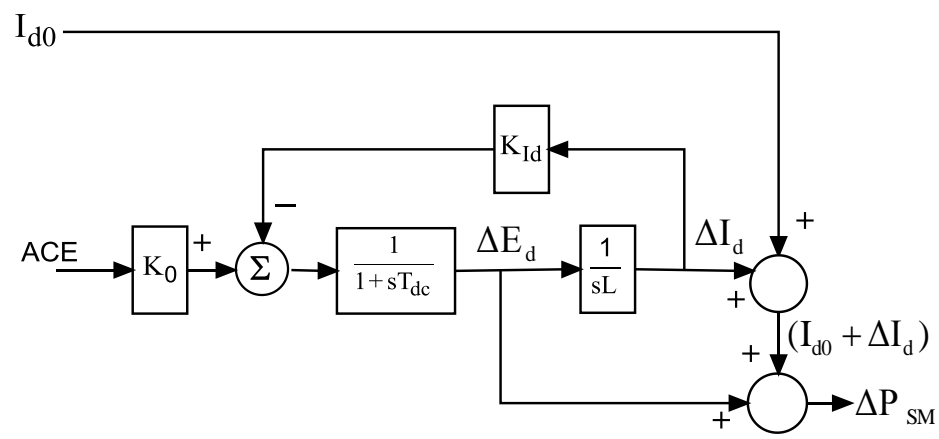

Fig.2. Transfer function model of SMES unit

The dynamic behavior of the LFC system is described by the state space equation:

$$
\dot{\mathrm{X}}=\mathrm{AX}+\mathrm{BU}+\mathrm{\Gamma D}
$$


Where $\mathbf{X}, \mathbf{U}$ and $\mathbf{D}$ are the state, control and disturbance vectors and $\mathbf{A}, \mathbf{B}$ and $\boldsymbol{\Gamma}$ are respectively system state matrix, control input matrix and disturbance input matrix of appropriate dimension $[9,10]$.

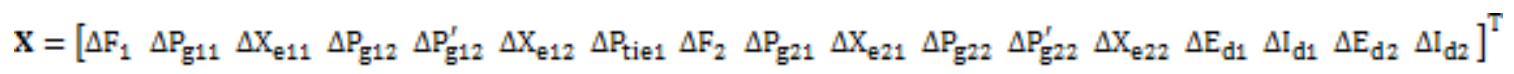

$$
\begin{aligned}
& \mathrm{U}=\left[\Delta \mathrm{P}_{\mathrm{c} 1} \Delta \mathrm{P}_{\mathrm{c} 2}\right]^{\mathrm{T}} \\
& \mathbf{D}=\left[\Delta \mathrm{P}_{\mathrm{d} 1} \Delta \mathrm{P}_{\mathrm{d} 2}\right]^{\mathrm{T}}
\end{aligned}
$$

The system matrices $\mathbf{A}, \mathbf{B}$ and $\Gamma$ can be obtained with the structure of the state, control and disturbance vectors and the transfer function block diagram representation of Fig.1.

The corresponding co-efficient matrices are obtained using the nominal system parameter values of the system given in Appendix. A step load disturbance of $1 \%$ has been considered as a disturbance in the system. For the frequency and tie-line power deviations to be zero at steady state, the Area Control Error (ACE) should be zero. To meet the above design requirement, the ACE is defined as:

$$
\mathrm{ACE}_{\mathrm{i}}=\Delta \mathrm{P}_{\text {tiei }}+\beta_{\mathrm{i}} \Delta \mathrm{F}_{\mathrm{i}}
$$

where ' $\mathrm{i}$ ' represents the control area and $\beta_{\mathrm{i}}$ is the frequency bias constant. The objective is to obtain the optimum value of the controller parameters which minimize the performance index $\mathbf{J}[9,11]$ :

$$
\mathrm{J}=\int_{0}^{t}\left(\Delta \mathrm{F}_{1}^{2}+\Delta \mathrm{P}_{\text {tie1 }}^{2}\right) d t
$$

The bat algorithm is used for the optimal designing of PI controller for LFC in two area interconnected power system to damp the power system oscillations. To simplify the analysis, the two interconnected areas are considered identical. The optimal parameter values are such that $\mathrm{K}_{\mathrm{p} 1}=\mathrm{K}_{\mathrm{p} 2}=\mathrm{K}_{\mathrm{p}}$ and $\mathrm{K}_{\mathrm{i} 1}=\mathrm{K}_{\mathrm{i} 2}=\mathrm{K}_{\mathrm{i}}$.

\section{BAT ALGORITHM}

The Bat Algorithm [4] is an optimization algorithm based on the echolocation behavior of bats. The capability of echolocation of bats is fascinating as these bats can find their prey and discriminate different types of insects even in complete darkness. The advanced capability of echolocation of bats has been used to solve different optimization problems. Echolocation of bats works as a type of sonar in bats, emits a loud and short pulse of sound, waits as it hits into an object and, after a fraction of time, the echo returns back to their ears . Thus, bats can compute how far they are from an object. In addition, this amazing orientation mechanism makes bats being able to distinguish the difference between an obstacle and a prey, allowing them to hunt even in complete darkness. Based on the behavior of the bats, Yang [4] has developed a new and interesting metaheuristic optimization technique called Bat Algorithm. Such technique has been developed to behave as a band of bats tracking prey/foods using their capability of echolocation.

\subsection{Bat algorithm idealized rules:}

1. All bats use echolocation to sense distance, and they also know the difference between food/prey and background barriers in some magical way.

2. Bats fly randomly with velocity $v_{i}$ at position $x_{i}$ with a fixed frequency $f_{\min }$, varying wavelength $\lambda$ and loudness $\mathrm{A}_{0}$ to search for prey. They can automatically adjust the wavelength (or frequency) of their emitted pulses and adjust the rate of pulse emission $r \in[0,1]$ depending on the proximity of their target.

3. Although the loudness can vary in many ways, it is assumed that the loudness varies from a large (positive) $\mathrm{A}_{0}$ to a minimum constant value $\mathrm{A}_{\min }$

\subsection{Pseudo code of the bat algorithm [4]}

Objective function $\mathrm{f}(\mathrm{x}), \mathrm{x}=\left(\mathrm{x}_{1}, \ldots, \mathrm{x}_{\mathrm{d}}\right)^{\mathrm{T}}$.

Step 1: Initialize the bat population $\mathrm{x}_{\mathrm{i}}=(\mathrm{i}=1,2, \ldots, \mathrm{n})$.

Step 2: Define pulse frequency $f_{i}$ at $x_{i}$

Step 3: Initialize pulse rates $r_{i}$ and the loudness $A_{i}$

Step 4: Check whether ( $\mathrm{t}<\mathrm{Max}$ - number of iterations), if yes go to step 5 , else go to step 11

Step 5: Generate new solutions by adjusting frequency, and updating velocities and solutions.

Step 6: Check whether $\left(\right.$ rand $>r_{i}$ ), if yes go to step 7, else go to step 8 .

Step 7: Select a solution among the best solutions and generate a local solution around the selected best solution. Generate a new solution by flying randomly.

Step 8: Check whether (rand $<A_{i} \& f\left(x_{i}\right)<f\left(x_{*}\right)$ ). If yes, go to step 9, else step 10.

Step 9: Accept the new solutions. Increase $r_{i}$ and reduce $A_{i}$

Step 10: Rank the bats and find the current best $\mathrm{X} *$ and go to step 4 .

Step 11: Print the Results. 
The positions $x_{i}$ and velocities $v_{i}$ in a dimensional search space are updated using the following equations. The new solutions $x_{i}^{t}$ and velocities $v_{i}^{t}$ at time step $t$ are given by:

$$
\begin{aligned}
& \mathrm{f}_{\mathrm{i}}=\mathrm{f}_{\text {min }}+\left(\mathrm{f}_{\max }-\mathrm{f}_{\min }\right) \\
& \mathrm{v}_{\mathrm{i}}^{\mathrm{t}}=\mathrm{v}_{\mathrm{i}-1}^{\mathrm{t}}+\left(\mathrm{x}_{\mathrm{i}}^{\mathrm{t}}-\mathrm{X}_{*}\right) \mathrm{f}_{\mathrm{i}} \\
& \mathrm{x}_{\mathrm{i}}^{\mathrm{t}}=\mathrm{x}_{\mathrm{i}-1}^{\mathrm{t}}+\mathrm{v}_{\mathrm{i}}^{\mathrm{t}}
\end{aligned}
$$

where, $\beta \in[0,1]$ is a random vector drawn from a uniform distribution. Here $\mathrm{x} *$ is the current global best location (solution) which is located after comparing all the solutions among all the $\mathrm{n}$ bats. As the product $\lambda_{\mathrm{i}} \mathrm{f}_{\mathrm{i}}$ is the velocity increment, we can use either $\mathrm{f}_{\mathrm{i}}\left(\right.$ or $\left.\lambda_{\mathrm{i}}\right)$ to adjust the velocity change while fixing the other factor $\lambda_{\mathrm{i}}\left(\right.$ or $\mathrm{f}_{\mathrm{i}}$ ), depending on the type of the problem of interest. Initially, each bat is randomly assigned a frequency which is drawn uniformly from $\left[\mathrm{f}_{\min }, \mathrm{f}_{\max }\right]$.For the local search part, once a solution is selected among the current best solutions, a new solution for each bat is generated locally using random walk:

$$
\mathrm{X}_{\text {new }}=\mathrm{X}_{\text {old }}+\epsilon \mathrm{A}^{\mathrm{t}}
$$

where, $\epsilon \in[-1,1]$ is a random number, while $A^{t}=\left\langle A_{i}^{t}\right\rangle$ is the average loudness of all the bats at this time step[7].

\section{OPTIMization OF PI CONTROller Parameters USING Bat Algorithm}

Bat algorithm is applied for optimizing the gains of a proportional plus integral controller for a two area interconnected thermal power system. The objective is to obtain the optimum values of the controller parameters which will minimize the performance index i.e. objective function, $\mathrm{J}$.

The objective function ( $\mathrm{J}$ ) is calculated for initial random set of $\mathrm{K}_{\mathrm{p}}$ and $\mathrm{K}_{\mathrm{i}}$. The objective function values are then mapped into a fitness value for each set of $\mathrm{K}_{\mathrm{p}}$ and $\mathrm{K}_{\mathrm{i}}$ in the initial population. After finding the initial fitness of the population, the values are updated based on movement, loudness and pulse rate. These steps are repeated until the values get converged producing optimum $K_{p}$ and $K_{i}$.

\section{SimUlation RESUlTS AND DisCUSSION}

The following parameters are used for BAT Algorithm in this study: Total population = 30; Number of iterations $=20$; Loudness $A=0.5$; Wavelength $r=0.5$; Frequency $f_{\min }=0.2, f_{\max }=0.9$.

The optimal gain parameters obtained for the system under study are shown in Table1. Simulation studies were carried out on a two area interconnected power system with SMES units for a step increase in demand of 0.01p.u, with the optimized control parameters obtained by implementing Bat algorithm. It is observed from Figs.3-5 that the output responses for the system with SMES unit have lesser over shoot and smaller settling time as those compared to the system without SMES unit. Table1 shows the system optimal gain values obtained by using proposed algorithm and settling time.

Table 1: Optimal gain parameters

\begin{tabular}{|c|c|c|c|c|c|}
\hline & \multirow{2}{*}{$\begin{array}{c}\text { Proportional Gain } \\
\left(\mathrm{K}_{\mathrm{p}}\right)\end{array}$} & $\begin{array}{c}\text { Integral Gain } \\
\left(\mathrm{K}_{\mathrm{i}}\right)\end{array}$ & \multicolumn{3}{|c|}{ Settling Time $(\mathrm{sec})$} \\
\cline { 3 - 7 } & 0.3535 & 0.9053 & 22.19 & 21.22 & 17.54 \\
\hline without SMES & 1.7570 & 1.8977 & 12.65 & 11.09 & 7.12 \\
\hline with SMES & & $\mathrm{F}_{1}$ & $\Delta \mathrm{F}_{2}$ & $\Delta \mathrm{P}_{\text {tie }}$ \\
\hline
\end{tabular}

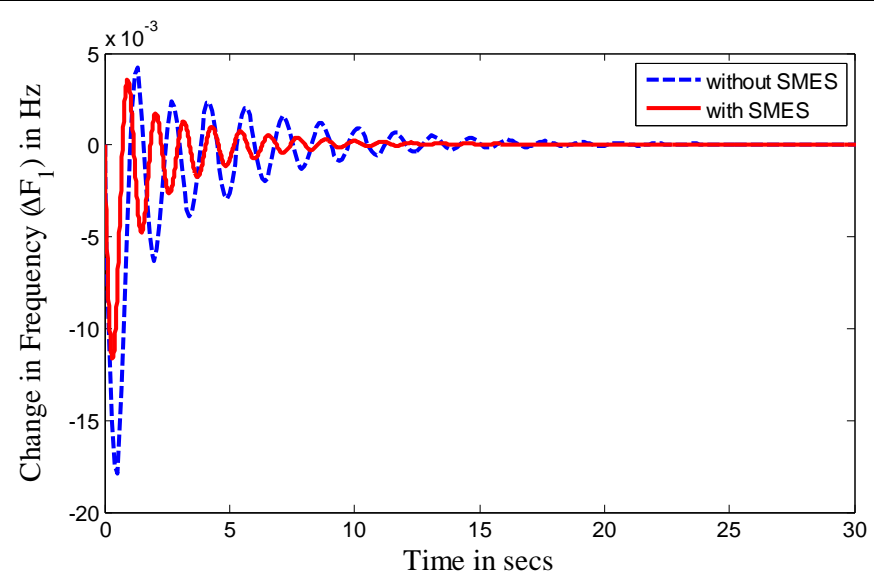

Fig.3. Change in frequency of first area for 0.01 p.u. change in area 1 


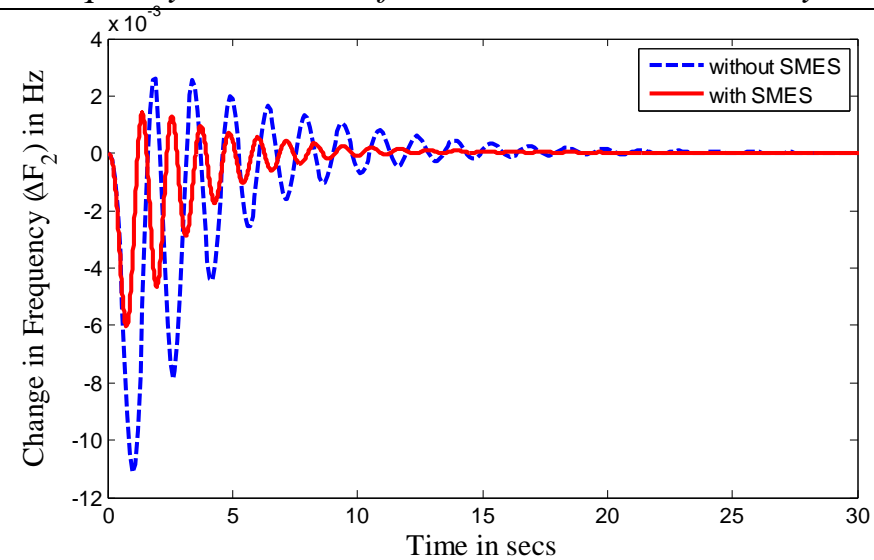

Fig.4. Change in frequency of second area for 0.01 p.u. change in area 1

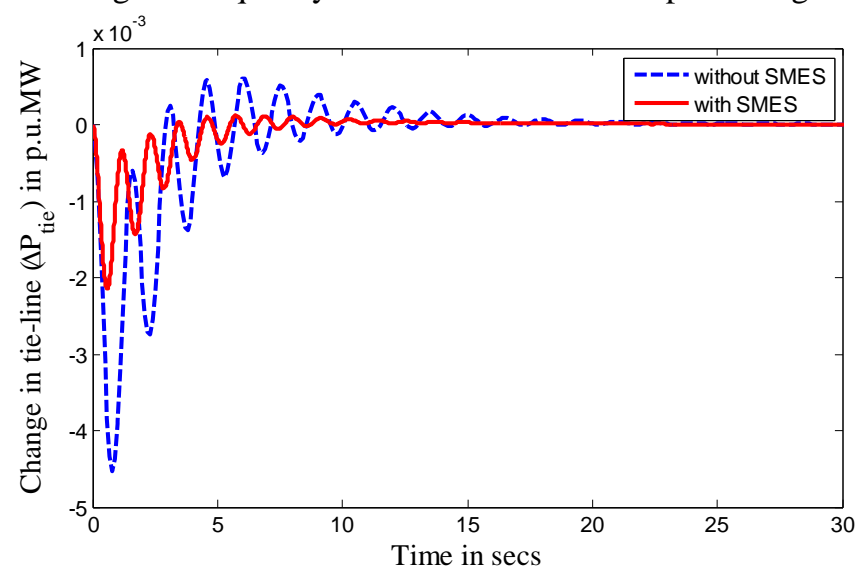

Fig.5. Change in tie-line power for 0.01 p.u. change in area 1

\section{CONCLUSION}

Tuning of controller parameters is essential for achieving good response with minimum error or disturbance while designing Load frequency controllers for interconnected power systems. The bat algorithm is implemented in a two area interconnected power system with SMES units to tune the parameters of PI controller. An Integral square error of the frequency deviation and tie-line power is taken as the objective function to improve the system response in terms of settling time and over shoot. Simulation results emphasize the effectiveness of the proposed algorithm. Besides simple architecture of the proposed algorithm, it has the potentiality to implement in real time applications.

\section{Appendix}

A. Nomenclature:

\begin{tabular}{|c|c|}
\hline $\mathrm{f}$ - Area frequency in $\mathrm{Hz}$ & $\mathrm{R}$ - Speed regulation of the governor in $\mathrm{Hz} /$ p.u.MW \\
\hline $\mathrm{J}_{\mathrm{i}}-$ Cost function of area $\mathrm{i}$ & $\mathrm{T}_{\mathrm{ps}}-$ Area time constant in secs \\
\hline $\mathrm{K}_{\mathrm{r}}$ - Reheat coefficient of the steam turbine & $\mathrm{K}_{\mathrm{ps}}-$ Gain associated with transfer function of the area in Hz/p.u. MW \\
\hline $\mathrm{K}_{\mathrm{p}}$ - Optimum proportional gain & $T_{r}-$ Reheat time constant of the steam turbine in secs \\
\hline $\mathrm{K}_{\mathrm{i}}$ - Optimum Integral gain & $T_{t}$ - Time constant of the steam turbine in secs \\
\hline $\mathrm{N}$ - Number of interconnected areas & $\mathrm{X}_{\mathrm{e}}$ - Governor valve position \\
\hline $\mathrm{P}_{\text {tie }}-$ The total power exchange of area in p.u.MW / Hz & $\mathrm{B}_{\mathrm{i}}$ - Frequency bias constant in p.u.MW / Hz \\
\hline $\mathrm{T}_{\mathrm{g}}-$ Time constant of the governing mechanism in secs & $\Delta$ - Incremental change of a variable \\
\hline $\mathrm{P}_{\mathrm{G}}-$ Mechanical (turbine) power output in p.u.MW & $\mathrm{I}_{\mathrm{d}}-\mathrm{SMES}$ current $(\mathrm{kA})$ \\
\hline $\mathrm{E}_{\mathrm{d}}-\mathrm{DC}$ voltage applied to inductor $(\mathrm{kV})$ & apf-area participation factor \\
\hline
\end{tabular}

B. Data of two-area interconnected power system $[3,10]$ :

\begin{tabular}{|l|l|}
\hline Rating of each area $=2000 \mathrm{MW}$ & $\mathrm{T}_{\mathrm{r} 12}=\mathrm{T}_{\mathrm{r} 22}=10 \mathrm{secs}$ \\
\hline Base power $=2000 \mathrm{MVA}$ & $\mathrm{K}_{\mathrm{ps} 1}=\mathrm{K}_{\mathrm{ps} 2}=120 \mathrm{~Hz} / \mathrm{p} . \mathrm{u} . \mathrm{MW}$ \\
\hline $\mathrm{f}^{0}=60 \mathrm{~Hz}$ & $\mathrm{~K}_{\mathrm{r} 12}=\mathrm{K}_{\mathrm{r} 22}=0.5$ \\
\hline $\mathrm{R}_{11}=\mathrm{R}_{12}=\mathrm{R}_{21}=\mathrm{R}_{22}=2.4 \mathrm{~Hz} /$ p.u. Hz. & $\mathrm{Tps} 1=\mathrm{Tps} 2=20 \mathrm{secs}$ \\
\hline $\mathrm{T}_{\mathrm{g} 11}=\mathrm{T}_{\mathrm{g} 12}=\mathrm{T}_{\mathrm{g} 21}=\mathrm{T}_{\mathrm{g} 22}=0.08 \mathrm{secs}$ & $\beta 1=\beta 2=0.425$ p.u. $\mathrm{M} . \mathrm{W} / \mathrm{Hz}$ \\
\hline $\mathrm{T}_{\mathrm{t} 11}=\mathrm{T}_{\mathrm{t} 12}=\mathrm{T}_{\mathrm{t} 21}=\mathrm{T}_{\mathrm{t} 22}=0.3 \mathrm{secs}$ & $2 \pi \mathrm{T}_{12}=0.545$ p.u. $\mathrm{MW} / \mathrm{Hz}$ \\
\hline $\mathrm{a}_{12}=-1$ & $\Delta \mathrm{P}_{\mathrm{d} 1}=0.01$ p.u. $\mathrm{MW} / \mathrm{Hz}$ \\
\hline$\Delta \mathrm{P}_{\mathrm{d} 1}=0.01$ p.u. MW/Hz & apf $_{11}=\operatorname{apf}_{12}=\mathrm{apf}_{21}=\mathrm{apf}_{22}=0.5$ \\
\hline
\end{tabular}


C. Data of SMES system [3]

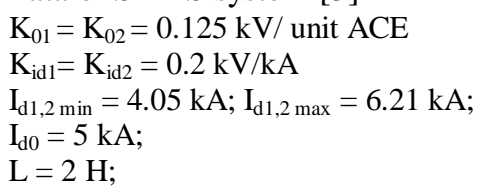

\section{ACKNOWLEDGEMENT}

The authors wish to thank the authorities of Annamalai University, Annamalai nagar, Chidambaram, Tamil Nadu, INDIA for the facilities provided to prepare this paper.

\section{Journal Papers:}

\section{REFERENCES}

[1] Naimul Hasan, An overview of AGC strategies in power system, International Journal of Emerging Technology and Advanced Engineering, 2(8), 2012,56-64.

[2] H.Shayeghi, H.A. Shayanfar, and A.Jalili, Load frequency control strategies: A state-of-the art survey for the researcher, Energy Conversion and Management, 50(2), 2009, 344-353.

[3] S. Banerjee., J. K. Chatterjee., and S. C. Tripathy, Application of magnetic energy storage unit as Load-frequency stabilizer, IEEE Transactions on Energy Conversion, 5(1),1990,46-51.

[4] X. S. Yang, A New Metaheuristic Bat-Inspired Algorithm, in J. R. Gonzalez et al (Ed.), Nature Inspired Cooperative Strategies for Optimization, (NISCO 2010)), Studies in Computational Intelligence, 284(Berlin: Springer, 2010),65-74.

[5] P. W. Tsai, Bat Algorithm Inspired Algorithm for Solving Numerical Optimization Problems, Applied Mechanics and Materials. 2011, 148-149: 134-137

[6] T.C. Bora, L.S. Coelho, L. Lebensztajn, Bat-Inspired Optimization Approach for the Brushless DC Wheel Motor Problem, IEEE Trans. Magnetics., 48(2), 2012, 947-950.

[7] P. Musikapun and P. Pongcharoen1, Solving Multi-Stage Multi-Machine Multi-Product Scheduling Problem Using Bat Algorithm, Proc. 2nd International Conf. on Management and Artificial Intelligence (IPEDR), Bangkok, Thailand, 2012,98-102

[8] X. S. Yang, M. Karamanoglu, S. Fong, Bat Algorithm for Topology Optimization in Microelectronic Applications, Proc. International Conf. on Future Generation Communication Technology, London, 2012 , 150-155

[9] J.Nanda and B. L. Kaul, Automatic generation control of an interconnected power system, IEE Proc., 125(5), 1978, 385-390.

[10] O.L.Elgerd and C.E.Fosha, Optimal megawatt frequency control of multi-area electrical energy systems, IEEE Trans. On PAS, $89(4), 1970,556-563$.

[11] S.Ganapathy, G.Sridhar, R.Balamurugan, S.Velusami, Design of Decentralized Load Frequency Controller for Interconnected Power Systems Using Differential Evolution Technique, IUP Journal of Electrical \& Electronics Engineering, IV(4),2011, 60-67. 